\title{
To Study of Spectrum of Inflammatory Bowel Disease in Western Rajasthan
}

\author{
Praveen Kumar Garg ${ }^{1}$, Taruna Choudhary², Bharat Gomtiwall ${ }^{3}$ \\ ${ }^{1}$ Associate Professor \& Unit Head, Department of Medicine, Government Medical College \&Bangur Hospital, Pali, Rajasthan, India, ${ }^{2}$ Assistant Professor, \\ Department of Pathology, Dr. S.N. Medical College, Jodhpur, Rajasthan, India, ${ }^{3}$ Senior Specialist, Department of Medicine, Government Bangur Hospital, Pali, \\ Rajasthan, India.
}

\section{Abstract}

Background: Inflammatory bowel disease denotes a group of disorders characterized by chronic intestinal inflammation, the etiology of which is unknown. In India Crohn's disease was thought to be uncommon and often treated as tuberculosis. The aim of this study the spectrum of inflammatory bowel disease in patients attending associated group of Hospitals, Dr. S.N. Medical College, Jodhpur, Western Rajasthan. Subjects and Methods: The present study was done on 210 patients presenting with history suggestive of inflammatory bowel disease. All of these patients were evaluated to confirm the diagnosis of IBD and were then differentiated between ulcerative colitis, Crohn's disease and indeterminate colitis. Those subjects already diagnosed with IBD were reviewed and evidences supporting IBD were accepted as cases in study. Results: A total of 2500 patients attended in gastroenterology clinic, out of which 210 patients were having symptoms suggestive of IBD. A total of 129 patients were diagnosed as IBD cases, in which $114(88.37 \%)$ were of ulcerative colitis and 15 (11.62\%) of Crohn's disease. Maximum number of UC patients i.e. $84(73.68 \%)$ and $12(80 \%)$ of CD patients were needed indefinite medical therapy to maintain remission of disease. Conclusion: We concluded that overall IBD is more common than expected in our community and Crohn's disease is being recognized now a days.

Keywords: Ulcerative Colitis (UC), Inflammatory Bowel Disease (IBD), Crohn's Disease (CD), Diagnosis.

Corresponding Author: Dr. Taruna Choudhary, Assistant Professor, Department of Pathology, Dr. S.N. Medical College, Jodhpur, Rajasthan, India.

Received: June 2019

Accepted: June 2019

\section{Introduction}

Inflammatory bowel disease denotes a group of disorders characterized by chronic intestinal inflammation, the etiology of which is unknown. It includes Crohn's disease (CD, ulcerative colitis (UC), and indeterminate colitis). UC is primarily a mucosal disease with almost exclusive colonic involvement in contrast to $\mathrm{CD}$ which may result in mucosal to transmural inflammation of virtually any part of gastrointestinal tract. ${ }^{[1]}$

Although the incidence and prevalence of UC \& CD are beginning to stabilize in high incidence areas such as Northern Europe and North America, they continue to rise in low incidence areas such as 1.4 million persons in United States and 2.2 million people in Europe suffer from these disease. Previously noted racial and ethnic differences seem to be narrowing. Differences in incidence across age, time and geographic region suggest that environmental factors significantly modify the expression of CD \& UC. The strongest environmental factors indentified are cigarette smoking and appendicectomy. Whether other factors such as diet, oral contraceptives, prenatal/childhood infections or atypical mycobacterial infections play a role in expression of inflammatory bowel disease remain unclear. Additional epidemiologic studies to define better the burden of illness, explore the mechanism of association with environmental factors, and identify new risk factors are needed. ${ }^{[2]}$

Several recent Asian studies confirm that the incidence and prevalence of both CD and UC is lower than that in North America and Europe. While this is true, Asia is a very diverse continent and marked difference have been reported in various geographic areas and an increased and prevalence of IBD is seen in the region.

Very few studies are conducted in this context in India. Sood et al, ${ }^{[3]}$ the largest population based screening study for ulcerative colitis from India with incidence rate of $6.02 / 100,000$ per year and crude prevalence rate of 44.3/100,000 in inhabitants in Punjab. The results of the other population based study from our country is available in abstract form.

In India Crohn's disease was thought to be uncommon and often treated as tuberculosis. In 1999 Mehta et al from India reported in their experience 5\% of children admitted for colonic disorders were diagnosed as UC. In, India, UC was first reported in 1964 and CD was considered almost nonexistent till 1986. During the last 10 years CD is being 
reported more frequently from different parts of India especially Southern India. In Rajasthan there is no study regarding epidemiology of IBD, so this study was conducted.

\section{Subjects and Methods}

The present study was done on 210 patients presenting with history suggestive of inflammatory bowel disease in the department of medicine \& gastroenterology in MG hospital, attached to Dr. SN Medical College, Jodhpur, Rajasthan.

All of these patients were evaluated to confirm the diagnosis of IBD and were then differentiated between ulcerative colitis, Crohn's disease and indeterminate colitis. Those subjects already diagnosed with IBD were reviewed and evidences supporting IBD were accepted as cases in study.

Upper GI endoscopy was done using video endoscopy by Olympus V series in upper GI symptomatology cases. Sigmoidoscopy procedure was performed after proctolysis edema and biopsy was taken.

\section{Diagnostic Criteria of IBD}

A diagnosis of "Definite" Ulcerative colitis was made if a suspected case met the following criteria: (1) typical history of diarrhea with or without blood and/or mucus in the stool. (2) typicalsigmoidoscopy/colonoscopic picture with diffusely granular, friable, or ulcerated mucosa without rectal sparing of skip lesions and (3) histopathological finding suggestive of ulcerative colitis.

A diagnosis of "definite" Crohn's disease was made if a suspected case met the following criteria: (1) history of chronic diarrhea and abdominal pain, and other symptoms like weight loss, fever (2) typical endoscopy features of crohn's disease (3) histopathological finding suggestive of Crohn's disease.

\section{Statistical Analysis}

Statistical analysis was performed using Epi info and SPSS software 16 version.

\section{Results}

A total of 2500 patients attended in gastroenterology clinic, out of which 210 patients were having symptoms suggestive of IBD. These patients were interviewed and examined and further evaluated. A total of 129 patients were diagnosed as IBD cases, in which $114(88.37 \%)$ were of ulcerative colitis and $15(11.62 \%)$ of Crohn's disease.

Our study showed that $61(53.5 \%)$ patients of UC and 10 (66.7\%) patients of $\mathrm{CD}$ were from 12-36 months range [Table 1]. In this study UC group $57.01 \%$ patients were having chronic continuous type of course whereas in $\mathrm{CD}$ group 7 (46.7\%) had chronic continuous and 7 (46.7\%) intermittent flare [Table 2].

Maximum number of UC patients i.e. 84 (73.68\%) and 12 (80\%) of CD patients were needed indefinite medical therapy to maintain remission of disease [Table 3].

\begin{tabular}{|c|c|c|c|c|c|c|c|c|}
\hline$\leq 12$ month & $13(56.5 \%)$ & $10(43.5 \%)$ & 23 & $20.2 \%$ & $2(50 \%)$ & $2(50 \%)$ & 4 & $26.7 \%$ \\
\hline$>36$ months & $12(40 \%)$ & $18(60 \%)$ & 30 & $26.3 \%$ & 0 & $1(100 \%)$ & 1 & $6.66 \%$ \\
\hline
\end{tabular}

Table 2: Course of Disease

\begin{tabular}{|c|c|c|c|c|c|c|c|c|}
\hline \multirow[t]{2}{*}{ Course } & \multicolumn{4}{|c|}{ Ulcerative colitis } & \multicolumn{4}{|c|}{ Crohn's disease } \\
\hline & Male & Female & Total & $\mathrm{N}=114$ & Male & Female & Total & $N=15$ \\
\hline Single episode & $14(66.7 \%)$ & $7(33.3 \%)$ & 21 & $18.4 \%$ & $1(100 \%)$ & 0 & 1 & $6.6 \%$ \\
\hline Chronic Continuous & $33(50.8 \%)$ & $32(49.2 \%)$ & 65 & $57.01 \%$ & $2(28.6 \%)$ & $5(71.4 \%)$ & 7 & $46.7 \%$ \\
\hline Intermittent Flare & $14(50 \%)$ & $14(50 \%)$ & 28 & $24.56 \%$ & $5(71.4 \%)$ & $2(28.6 \%)$ & 7 & $46.7 \%$ \\
\hline
\end{tabular}

\begin{tabular}{|c|c|c|c|c|c|c|c|c|}
\hline Taper Medical & $16(59.2 \%)$ & $11(40.8 \%)$ & 27 & $23.68 \%$ & 0 & $1(100 \%)$ & 1 & $6.66 \%$ \\
\hline Medical Therapy & $43(51.2 \%)$ & $41(48.2 \%)$ & 84 & $73.68 \%$ & $6(50 \%)$ & $6(50 \%)$ & 12 & $80 \%$ \\
\hline
\end{tabular}

\section{Discussion}

In present study we included all the patients attending outdoor \& indoor in dept. of medicine and gastroenterology with history of diarrhea of $>4$ weeks with or without blood in stool. A total of 129 patients were diagnosed as IBD cases, in which $114(88.37 \%)$ were of ulcerative colitis and $15(11.62 \%)$ of Crohn's disease.

In UC group, out of 114 patients, $61(53.5 \%)$ were male and $53(46.5 \%)$ were female patients. Similarly in Crohn's cases, out of 15 patients, $7(46.6 \%)$ were male and 8 $(53.3 \%)$ were female. This is in accordance with previous 
study by Ekbam A et al, ${ }^{[4]}$ and Garrido A et al,,${ }^{[5]}$ Some of previous study like LassloLakatos et al, ${ }^{[6]}$ and Cao Qian et $\mathrm{al},{ }^{[7]}$ reported male preponderance in $\mathrm{UC}$ and $\mathrm{CD}$. Whereas male Rodringo $\mathrm{L}$ et al, ${ }^{[8]}$ and Edoriad $\mathrm{A}$ et al, ${ }^{[9]}$ reported female preponderance in both $\mathrm{UC}$ and $\mathrm{CD}$. Thus it is concluded that earlier studies was showing male preponderance in $\mathrm{CD}$ group, but recent studies included present study reported almost equal distribution of disease, both UC as well as CD in male and female. Prevalence of UC is much more than CD in IBD patients.

Duration of symptoms in IBD patients was studied. In UC group, $20.1 \%$ patients were suffering from less than 12 months, 53.5\% were suffering from 12-36 months and rests were suffering from more than 36 months. Similarly in CD patients, $26.6 \%$ patients were suffering from less than 12 months, $66.6 \%$ were suffering from 12-36 months and rests were suffering from more than 36 months. This is in accordance with Sood A et al, ${ }^{[3]}$ in UC patients and Farmer et al in CD patients.

In UC, single episode was seen in $18.4 \%$, chronic continuous in $57.01 \%$ \& intermittent flare in $24.56 \%$ cases. Hendriksen et al, ${ }^{[10]}$ reported in their study that $42 \%$ to $65 \%$ of UC patients have intermittent course and 5\% to $10 \%$ of patients have chronic continuous course. In $\mathrm{CD}$, single episode was seen in $6.1 \%$, chronic continuous course in $46.6 \%$ \& intermittent flare in $46.6 \%$ cases.

Moum B et al, ${ }^{[11]}$ reported that $22 \%$ of $\mathrm{CD}$ patients have shown chronic continuous and 53\% have intermittent flare course.

Complication were more common in CD (40\%) as compared to UC $(3.5 \%)(\mathrm{p}<0.001)$. This is in accordance with Vind I et al, ${ }^{[12]}$ and Garrido A et al. ${ }^{[5]}$

Colectomy was done in $2.6 \%$ of UC patients and fistulectomy in $6.6 \%$ of $\mathrm{CD}$ patients. One patient was operated for intestinal obstruction by resection and anastomosis this is in accordance with Hendriksen $\mathrm{C}$ et al. ${ }^{[10]}$

\section{Conclusion}

We concluded that overall IBD is more common than expected in our community and Crohn's disease is being recognized now a days.

\section{References}

1. Ravi Kumar M, Sandhu BK: Epidemiology of inflammatory bowel disease in childhood. Indian J. Pediatric, 2006;73:717-721.

2. Edward V. Loftus JR. Clinical epidemiology of IBD Gastroenterol 2004;12:1504-17.

3. A Sood, V Midha, N Sood, AS Bhatia \& G Avasthi. Incidence \& prevalence of ulcerative colitis North India, Punjab. Gut 2003;52:1587-1590.

4. Ekbom A, Helmick C, Zack M. The epidemiology of IBD, a large population based study in Sweden. Gastroenterology, 1991;10(2):35-8.

5. Garrido A, Martiner MJ, Ortega JA. Epidemiology of chronic inflammatory bowel disease in the Northern area of Huelva. Rev EspEnferm Dig,2004;96:687-694.

6. Laszlo Lakatos, Gabor Mester, ZsusannaErdelyi. Striking elevation in incidence \& prevalence of IBD in a province of Western Hungary between, 1977-2001. World J Gastroenterol 2004;10(3):404-409.

7. Cao Qian, Si Jian-Min, Gao Min. Clinical presentation of inflammatory bowel disease: a hospital based retrospective study of 379 patients in China. Chinese Med Journal 2005;118(9):747-752.

8. Rodrigo L, Riestra S Nino P. A population based study on the incidence of inflammatory bowel disease in Oviedo (Northern Spain). Revista Espanola de EnfermedodesDigestivas. 2004;96(5):296-305.

9. Edourd A, Pallaud M, Merle S. Incidence of inflammatory bowel disease in French West Indies (1997-1994).

10. Henriksen C, Kreiner S, Binder V' Long term prognosis in ulcerative colitis bsed on results from a regional patient group from the country of Copenhagen. Gut 1985;26:158.

11. Moum B, Ekbom A, Vatn MH et al. Clinical course during first year after diagnosis in ulcerative colitis \& Crohn's disease: results of a large prospective population based study in south western Norway, 1990-1993. Scan J Gastroenterology 1997;32:1005.

12. Vind I, Riis L, Jess T, the DCCD study group. Increasing incidences of inflammatory bowel disease and decreasing surgery rates in Copenhagen city \& country, 2003-2005: a population based study from the Danish Crohn Colitis data base. Americal J. of Gastroenterology, 2006;101(6):1274-82.

Copyright: () the author(s), 2019. It is an open-access article distributed under the terms of the Creative Commons Attribution License (CC BY 4.0), which permits authors to retain ownership of the copyright for their content, and allow anyone to download, reuse, reprint, modify, distribute and/or copy the content as long as the original authors and source are cited.

How to cite this article: Garg PK, Choudhary T, Gomtiwall B. To Study of Spectrum of Inflammatory Bowel Disease in Western Rajasthan.Asian J. Med. Res. 2019;8:(2): ME15-ME17.

DOI: dx.doi.org/10.21276/ajmr.2019.8.2.ME06

Source of Support: Nil, Conflict of Interest: None declared. 